\title{
10.5005/jp-joumals-10023-1045 \\ CASE REPORT \\ Stridor due to Bilateral Implant Migration 5 Years after Bilateral Medialization Laryngoplasty
}

\author{
Nupur Kapoor Nerurkar, Sunita Chhapola Shukla
}

\begin{abstract}
Implants like silastic, titanium, Gore-Tex and autologous cartilage have been used for type I laryngoplasty. Though rare, implant extrusion or migration, wound infection and airway compromise are some of the complications of medialization laryngoplasty surgery irrespective of the implant used. We document a rare case of bilateral implant migration in a patient who had undergone bilateral medialization laryngoplasty 5 years ago. Gore-Tex extrusion resulted in stridor 5 years after the initial surgery. Endoscopic removal of the extruded implant is advised, if feasible, without the need for tracheostomy or transcervical approach. An update on current knowledge and management of implant extrusion or migration is discussed.
\end{abstract}

Keywords: Bilateral medialization laryngoplasty, Thyroplasty, Gore-Tex, Implant migration, Implant extrusion, Stridor.

How to cite this article: Nerurkar NK, Shukla SC. Stridor due to Bilateral Implant Migration 5 Y ears after Bilateral Medialization Laryngoplasty. Int J Phonosurg and Laryngol 2012;2(2):82-84.

\section{Source of support $\mathrm{Nil}$}

\section{Conflict of interest: None}

\section{INTRODUCTION}

M edialization laryngoplasty phonosurgeries have emerged as a dominant surgical intervention for paralytic and paretic dysphonia. Various modifications in surgical techniques, first popularized by Isshiki in 1975, have taken place over the years. The indications and techniques of bilateral medialization laryngoplasty have continued to evolve since K auffman described it for vocal fold bowing in 1989. Presbylaryngis, bilateral vocal fold paresis, sulcus vocalis, unilateral vocal fold paralysis with contralateral bowing are some of the indications of bilateral medialization laryngoplasty. M cCulloch and Hoffman described the first vocal fold medialization by Gore-Tex (expanded polytetrafluoroethylene) in $1998 .{ }^{1}$ Gore-Tex is a biocompatible implant material which has gained popularity as it is adjustable within a small cartilaginous window. ${ }^{1}$ Complications like implant migration and extrusion, wound infection and airway compromise do occasionally occur following thyroplasties. ${ }^{2-6} \mathrm{~A}$ irway obstruction is uncommon yet life-threatening when it occurs, and one death has been reported. ${ }^{7}$ Hematoma and implant extrusion can lead to airway obstruction preoperatively.

\section{CASE REPORT}

A 49-year-old female patient was referred to our hospital with chief complaints of stridor since 5 days, dyspnea on exertion since 3 months and hoarseness of voice since last 3 years. Patient had undergone bilateral medialization laryngoplasty for vocal fold bowing 5 years back at another center. The surgical notes suggested right silastic medialization and left Gore-Tex medialization. Further details were not available. Though postoperatively the voice improved, there was deterioration within 2 years. V ideostroboscopy revealed bilateral sulcus vocal is in mobile vocal folds. There wereflorid granulations in subglottic area narrowing the airway. The patient was admitted and intravenous steroids and steroid nebulization was started. An urgent computed tomography (CT) scan with contrast reveal ed both the implants at the level of cricoid cartilage. The left-sided Gore-Tex implant was $2 \mathrm{~cm}$ bel ow the true vocal fold and right-sided silastic implant was $2.3 \mathrm{~cm}$ below the vocal folds (Fig. 1). The patient was intubated with a

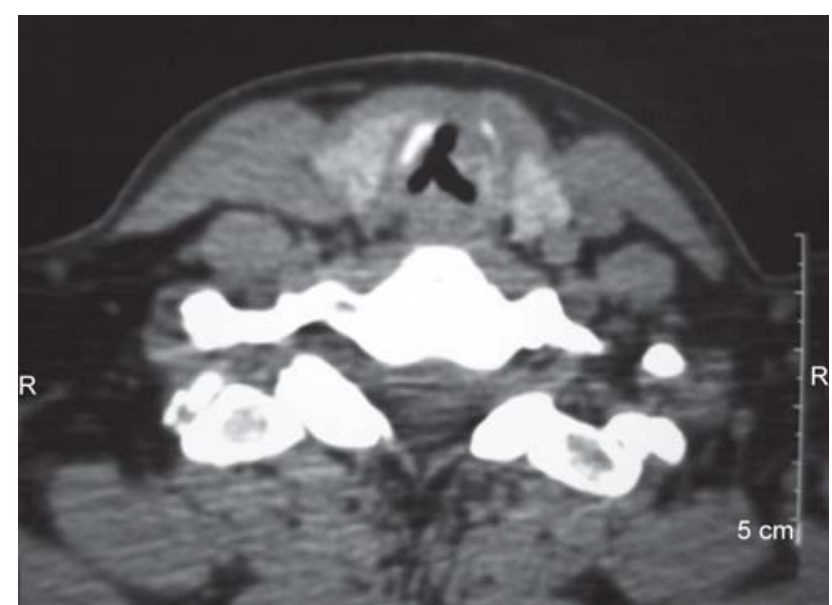

Fig. 1: CT scan showing bosselated appearance of Gore-Tex on the right side at the subglottic level

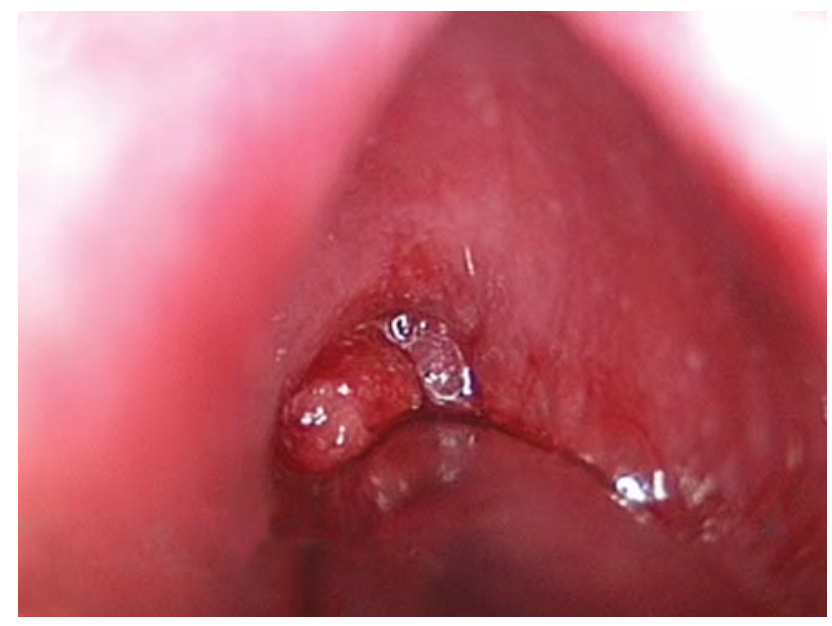

Fig. 2: Subglottic granulations with the tip of extruded Gore-Tex 
Stridor due to Bilateral Implant Migration 5 Y ears after Bilateral Medialization Laryngoplasty

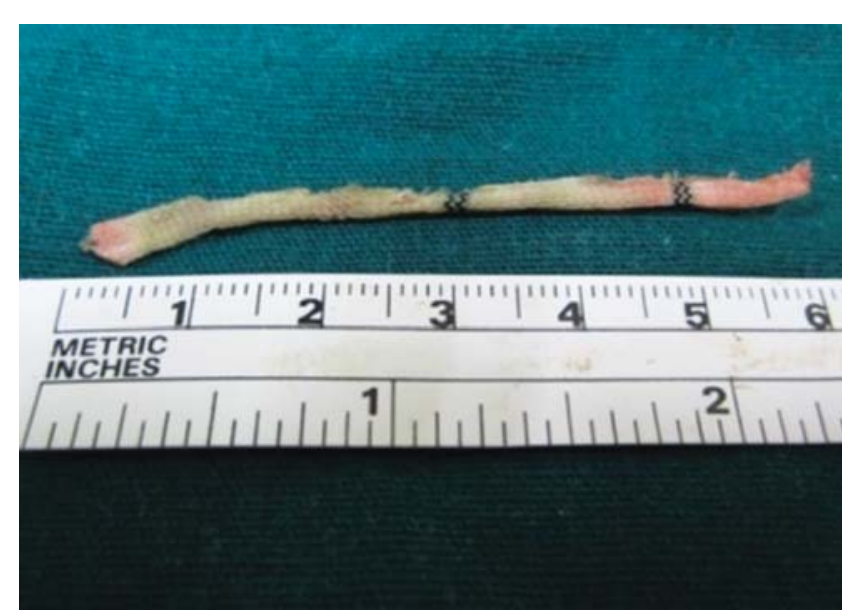

Fig. 3: Extruded Gore-Tex removed endoscopically

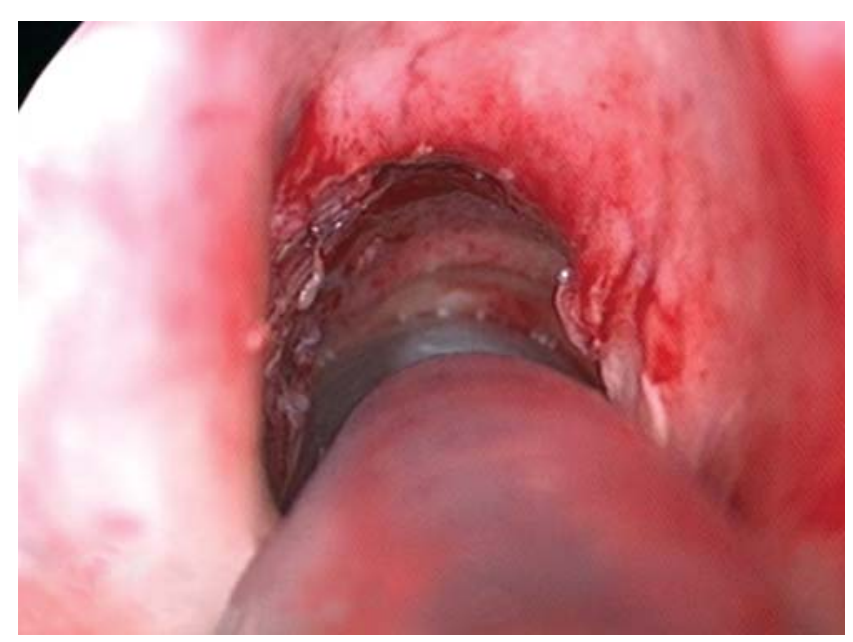

Fig. 4: Airway after removing Gore-Tex and granulations

five number $M$ allinckrodt laser safe metal endotracheal tube. A small tip of the extruded Gore-Tex was visible between the granulations (Fig. 2) and was gently removed endoscopically (Fig. 3). The granulations were excised with the $\mathrm{CO}_{2}$ laser and hemostasis was achieved. M itomycin $\mathrm{C}$, $2 \mathrm{mg} / \mathrm{ml}$ was applied at the granulation site for 5 minutes. On the right side, the mucosa appeared intact and the airway had dramatically improved (Fig. 4). Thus, a decision was made to avoid an external open approach for removing the migrated silastic. The patient had an uneventful postoperative recovery.

\section{DISCUSSION}

Laryngeal framework surgery has become a preferred method of surgical intervention for glottal incompetence. Payr was the first to report medialization of vocal fold in $1915 .^{8}$ The modern laryngoplasty surgery has evolved from the extensive work done by Isshiki in $1975 .{ }^{9}$ The indications of laryngeal framework surgery have extended to the management of atrophy, sulcus vocal is, defects from trauma or cancer resection. ${ }^{10,11} \mathrm{~A}$ long with advances in surgical techniques, the implants used have also evolved. Silastic, titanium, Gore-Tex and autologous cartilages all have been used for medialization laryngoplasty. The most commonly used are silastic and Gore-Tex implants. Gore-Tex is malleable, requires a small thyroplasty window and is considered to be reversible and revisable. ${ }^{12-14}$ However, complications with Gore-Tex do occur most commonly due to excessive elevation of the inner perichondrial pocket. This is responsible for implant migration, which could be a delayed complication also. G reat care must be taken during blunt dissection and placement of Gore-Tex into soft tissue defects, because recalcitrant granulation develops, if there is transepithelial exposure. ${ }^{14,15}$

Ustundag et al conducted a study on rabbits for medialization laryngoplasty comparing silastic, Gore-Tex and human cartilages for medial ization laryngoplasty. ${ }^{16}$ The allergic reactions and inflammatory responses were minimal for silastic, followed by Gore-Tex and lastly for cartilages. He al so suggested G ore-T ex's potential for migration within paraglottic space either acutely or overtime. A fibrous capsule barrier which forms between host tissue and implant material was more for silicone as compared to Gore-Tex. A bility of the implant to live in the host for a long period without being reabsorbed depends on this fibrous barrier. It also determines the ability of the implant material to be removed or replaced. ${ }^{17}$ Though Gore-Tex is considered highly biocompatible and is al so extensively used in vascular and plastic augmentation surgeries, risk of granulomatous reaction remains unpredictable and if possible should not be used in young adults and children.

Gore-Tex extrusion has been discussed in the literature, though very few authors have reported it. Only one case have been reported by M ohanty et $\mathrm{al}^{12}(\mathrm{n}=47)$, Giovanni et $\mathrm{al}^{13}(n=13)$ and Zeitels et $\mathrm{al}^{14}(n=142)$. Our was a rare case of bilateral migration of implants in a case of bilateral medialization laryngoplasty done for bowing of vocal fold causing stridor on exertion and hoarseness of voice. The migration of implants occurred 5 years after bilateral medialization laryngoplasty, thus causing airway obstruction. We could find only one case of Gore-Tex extrusion into the subglottic area, 49 months after the surgery, which was removed endoscopically. ${ }^{18}$

If implant extrusion is associated with an intralaryngeal mucosal violation, removal through an external neck approach results in contamination of wound and immediate reimplantation is not safe because of infection risk. ${ }^{19}$ Such cases can be tackled safely endoscopically. 


\section{CONCLUSION}

Gore-Tex is widely used as an implant for medialization laryngoplasty. Implant extrusion or migration, wound infection and airway compromise are some of the possible complications of medialization laryngoplasty surgery. M igration or extrusion of implants can occur many months or years after medialization surgery. Endoscopic removal of the extruded implant is advised, if feasible, as it avoids the need for tracheostomy or transcervical approach.

\section{REFERENCES}

1. M cCulloch PM, Hoffman HT. M edialization laryngoplasty with expanded polytetrafluoroethylene. Surgical technique and preliminary results. A nnals Otol Rhinol Laryngol 1998;107: 427-32.

2. Kartha S, Y oung K, M ohan S. Complications of medialization laryngoplasty (thyroplasty type-I). Int J Phonosurg Laryngol 2011 J an-J un;1(1):1-3.

3. Neterville JL, Stone RE, Luken ES, Civantos FS, Ossoff RH. Silastic medial isation and arytenoids adduction: The $V$ anderbilt experience. A nn Otol Rhinol Laryngol 1993;102:413-24.

4. W 00 P. A rytenoid adduction and medialization laryngoplasty. Otolaryngol Clin North A m 2000;33(4):817-39.

5. A braham M T, Gonen M, K raus DH. Complications of type I thyroplasty and arytenoid adduction. Laryngoscope 2001;111:1322-29.

6. Koufman JA, Isaacsin G. Laryngoplastic phonosurgery. Otolaryngologic Clin N orth A m 1991;24:1151-77.

7. Maves MD, M cCabe BF, Gray S. Phonosurgery: Indications and pitfalls. A nn Otol R hinol Laryngol 1989;99:577-80.

8. Payr E. Plastik am schildknorpel zur Behebung der Folgen einseitiger Stimmbandlahmung. Dtsch Med Wochenschr 1915;43:1265-70.

9. Isshiki N, M orita $\mathrm{H}, \mathrm{O}$ kamura $\mathrm{H}, \mathrm{H}$ iramoto $\mathrm{M}$. Thyroplasty as a new phonosurgical technique. A cta Otolaryngol (Stockh) 1975;78:451-57.

10. Koufman JA. Surgical correction of dysphonia due to bowing of the vocal cords. A nn Otol Rhinol Laryngol 1989;98:41-45.
11. Postma GN, Blalock PD, Koufman J A. Bilateral medialization laryngoplasty. Laryngoscope 1998 Oct;108:1429-34.

12. Mohanty S, Gopinath M, Subramanian M. Gore-Tex medialization thryroplasty in patients with unilateral vocal cord paralysis: An audit of 47 cases. Int J Phonosurg L aryngol 2011 Jan-J un;1(1):11-13.

13. Giovanni A, Vallicioni JM, Gras R, Zanaret M. Clinical experience with Gore-Tex for vocal fold medialization. L aryngoscope $1999 \mathrm{Feb} ; 109: 284-88$.

14. Zeitels SM, M auri M, Dailey SH. M edialization laryngoplasty with Gore-Tex for voice restoration secondary to glottal incompetence. Indications and observations. Ann Otol R hinol L aryngol 2003Feb;112(2):180-84.

15. Stasney CR. B eaver ME, R odriguez M. M inifenestration type I thyroplasty using an expanded polytetrafluoroethylene implant. J V oice 2001;15:151-57.

16. U stundag E, B oyaci Z, Keskin G, K aur A, Ozkarakas H. Soft tissue response of the larynx to silicone, Gore-Tex and irradiated cartilage implants. Laryngoscope 2005 J un;115:1009-14.

17. Cashman S, Simpson CB, M cguff HS. Soft tissue response of the rabbit larynx to Gore-Tex implant. A nnals Otol Rhinol Laryngol 2002;111:977-82.

18. L accourreye $0, H$ ans $S$. Endolaryngeal extrusion of expanded polytetrafluoroethylene implant after medialization thyroplasty. A nn Otol R hinol Laryngol 2003;112:962-64.

19. Halum SL, Postma GN, K oufman JA. Endoscopic management of extruding medialization laryngoplasty implants. Laryngoscope 2005 J un;115:1051-54.

\section{ABOUT THE AUTHORS}

\section{Nupur Kapoor Nerurkar (Corresponding Author)}

Consultant Laryngologist, Department of ENT, M umbai Port Trust Hospital, Wadala (E), M umbai, M aharashtra, India e-mail: nupurkapoor@yahoo.com

\section{Sunita Chhapola Shukla}

Clinical A ssistant, Department of ENT, M umbai Port Trust H ospital M umbai, M aharashtra, India 